\title{
Sulfur Cycling During Burial Diagenesis in Marine Carbonates
}

\author{
LEI JiAnG ${ }^{1,2}$, MOJTABA FAKHRAEE ${ }^{3}$, \\ Chunfang CAI ${ }^{1,3}$
}

${ }^{1}$ Key Laboratory of Petroleum Resources Research, Institute of Geology and Geophysics, Chinese Academy of Sciences, Beijing 100029, China (lei.jiang@mail.iggcas.ac.cn)

${ }^{2}$ Institutions of Earth Science, Chinese Academy of Sciences, Beijing 100029, China

${ }^{3}$ Department of Geology and Geophysics, Yale University, New Haven, CT 06511, USA

Reduction of sulfate to sulfide plays a crucial role in global sulfur cycle. However, there is no comprehensive study has included the effects from both microbial sulfate reduction (MSR) and thermochemical sulfate reduction (TSR), in modulation of $\delta^{34} \mathrm{~S}$ signals. Here we report an occurrence of various types of sulfur-bearing components from the Cambrian-Ordovician carbonate system in the Tarim Basin, NW China, coupled with a well-established diagenesis framework. Our results indicate that most of the sulfur-bearing species possess $\delta^{34} \mathrm{~S}$ values slightly lower than the source sulfate and the sulfide generated by TSR, but substantially higher than the $\delta^{34} \mathrm{~S}$ values of sulfide that evidently is consistent with MSR. Hence, a mixing of sulfide from both MSR and TSR was a most plausible scenario. Building upon this hypothesis, a new sulfur diagenesis model was built for quantifying pooled $\mathrm{H}_{2} \mathrm{~S}$ from MSR and TSR, thus can help better determine the origin of sulfur-bearing species in many deep burial carbonate systems, and the Neoproterozoic super-heavy pyrite. Our results, further, invoke a deeper look at diagenesis to gain a better mechanistic understanding of the primary signals (e.g., $\delta^{34} \mathrm{~S}$ and $\left.\delta^{13} \mathrm{C}\right)$ in marine carbonates, e.g., the Neoproterozoic ones deposited at the dawn of marine animal life. 